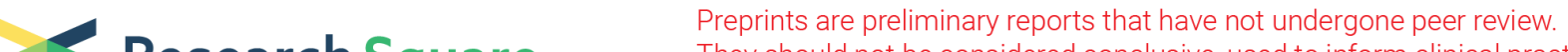 Research Square They should not be considered conclusive, used to inform clinical practice, or referenced by the media as validated information.
}

\section{Malignancy in Non-HIV Infected Patients with Cryptococcal Meningitis: A Retrospective Study}

\section{Xiaofeng Xu}

Third Affiliated Hospital of Sun Yat-Sen University

\section{Liping Cao}

the first affilisted hostpital of Guizhou University of traditional chinese medicine

\section{Yijie Wang}

Third Affiliated Hospital of Sun Yat-Sen University

Jia Liu

Third Affiliated Hospital of Sun Yat-Sen University

\section{Qing Dong}

Third Affiliated Hospital of Sun Yat-Sen University

\section{Chunling Liang}

Third Affiliated Hospital of Sun Yat-Sen University

Ying Jiang ( $\sim$ jiangying722@163.com )

Third Affiliated Hospital of Sun Yat-Sen University

\section{Fuhua Peng}

Third Affiliated Hospital of Sun Yat-Sen University

\section{Research Article}

Keywords: cryptococcal meningitis, malignancy, positron emission computed tomography

Posted Date: September 10th, 2020

DOI: https://doi.org/10.21203/rs.3.rs-73609/v1

License: (ㅇ) (1) This work is licensed under a Creative Commons Attribution 4.0 International License. Read Full License 


\section{Abstract}

\section{Background.}

Cryptococcal meningitis (CM) was found to be coexist with malignancy in non-human immunodeficiency virus (HIV) infected patients. The purpose of this study was to evaluate the clinical characteristics and therapeutic outcomes of CM in non-HIV infected patients with malignancy.

\section{Methods.}

A total of $320 \mathrm{CM}$ patients were enrolled for analysis from January 2013-May 2019. One hundred and four patients underwent positron emission computed tomography (PET-CT) examination. The demographics, clinical characteristics, microbiological, radiological, therapeutic outcomes were analyzed in CM patients with and without malignancy.

\section{Results.}

Twelve patients with malignancy were found, of which 7 malignancy before CM (MBC), 5 malignancy after CM (MAC). CM patients with malignancy were older than non-malignancy ones. The prognosis of MBC patients was comparable to that of non-malignancy patients, but was extremely poor in MAC patients. Four out of $5 \mathrm{CM}$ patients, who was suggested diagnosis as malignancy by PET-CT, were finally confirmed.

\section{Conclusions.}

This study found an increase rate of solid malignancies in CM patients. Screening malignancy in older CM patients was very important because it is closely related to prognosis and might affect treatment strategy. PETCT might be a useful tool for early malignancy screening in CM.

\section{Introduction}

Cryptococcal meningitis (CM) is the one of the most common opportunistic infection and often occurs in the patients with human immunodeficiency virus (HIV) infection [1, 2]. In non-HIV endemic areas, CM appears in a growing number of other forms of natural or iatrogenic immunosuppressive patients [3]. In China, about one-third of non-HIV CM patients have predisposing factors, and the prognosis of these people does not seem to be significantly different from that of the immunocompetent population [4].

Malignancy is also considered to be immune-related diseases. HIV patients and genetic model animals with immunodeficiency has shown an increase in the incidence of malignancy formation $[5,6]$. Previous retrospective studies have shown that the incidence of cryptococcal infections is higher in the patients with malignancy, especially in hematological malignancy [7-9]. Though the $\mathrm{CM}$ and malignancy may associate with immunodeficiency at the same time, the coexistence of malignancy and CM in non-HIV patients is unclear now. In addition, the types of malignancies and their effect on CM prognosis need to be further studied.

To the best of our knowledge, no studies have been conducted to evaluate the clinical characteristics and therapeutic outcomes of CM in non-HIV infected patients with malignancy. The objective of this study is to analyze the epidemiological and clinical data of malignancy in non-HIV patients with CM, and assess the 
application of positron emission computed tomography (PET-CT) in the diagnosis of malignancy in the CM population.

\section{Methods}

\section{Study populations}

This is a retrospective study approved by the Medical Ethics Committee of the Third Affiliated Hospital of Sun Yat-sen University. All study participants have provided written consent for research and publication.

Records of all patients diagnosed with definite CM from January 2013-May 2019 were examined. Figure 1 illustrates the flowchart for the 357 recruited non-HIV infected CM patients. The enrolled CM patients were divided into three groups according to the discovery of malignancy: 1) no malignancy, 2) malignancy before $\mathrm{CM}$ (MBC), 3) malignancy after CM (MAC). Definite CM were identified by a positive result of India ink smear, microbiology culture in cerebrospinal fluid (CSF) and histopathological finding in meninges or brain parenchyma (5 to $10 \mu \mathrm{m}$ encapsulated yeasts). The diagnosis of malignancy before admission depended on the medical history. Patients newly diagnosed with malignancy after admission were confirmed by typical imaging findings and tissue pathology (surgery or biopsy). Patients were excluded if they had a history of immunodeficiency, such as HIV infection, rheumatic diseases, use of immunosuppressants and corticosteroids.

\section{PET-CT examination}

Among these $320 \mathrm{CM}$ patients, 104 of them underwent PET-CT examination. These patients were fasted for at least 4 hours with glucose levels less than $150 \mathrm{mg} / \mathrm{dL}$ before starting the scan. PET images of the whole body were obtained by using a PET-CT scanner (Discovery Elite, GE healthcare, Chicago, IL, USA) after intravenous injection of $5.2 \mathrm{MBq}$ per kilogram body weight 18 -fluorodeoxyglucose ( ${ }^{18} \mathrm{~F}-\mathrm{FDG}$ ) up to maximum of $370 \mathrm{MBq}$ (10 $\mathrm{mCi})$. The 3D PET data and CT images were reconstructed for diagnosis.

\section{Treatment and outcomes}

Antifungal treatment was based on amphotericin B, usually in combination with fluconazole/voriconazole and 5flucytosine. Combination therapy will sterilize CSF within 2 weeks of treatment in most immunocompetent patients [10], so the patient's first therapeutic evaluation was performed 2 weeks after using the standard antifungal treatment described above. With reference to previous study [4], "response" was defined as survival within 2 weeks with relief of symptoms and clinical signs, improvement in CSF chemistry and cell count, reduce of cryptococcus counts in CSF. Our standard treatment composed by three stages according to the guidelines, including induction, consolidation and maintenance stages [11]. If the patient has completed the standard treatment stages, with the clinical symptoms disappear, and negative CSF cryptococcus result, CM was considered to be cured, and patients were marked as "success". The patients were follow-up with regular rehospitalization, outpatient visits and telephone after discharge until got "success". The cause and time of death were recorded during follow-up. The cause of death within 6 months in these patients was analyzed. If the patient's death was due to an exacerbation of the central nerve system infection (assessed by radiography and CSF examination) and its associated complications, the cause of death was considered to be "CM-related". If the patient's death was due to malignancy, which caused organ dysfunction or associated complications, the death 
was considered to be "malignancy-related". The cause of death which cannot be attributed to the above two situations was considered as "other".

\section{Statistical analysis}

All statistical analyses were performed using SPSS (version 16.0, Chicago, IL, USA). Continuous data were analyzed using Student's $t$-test after confirming a normal distribution using the Shapiro-Wilk test. Mann-Whitney test was used if the data was not a normal distribution. Chi-square analysis was used to analyze categorical variables. Fisher's exact test was an alternative, if the data does not meet the chi-square requirements. Survival was defined as the time from the diagnosis of $\mathrm{CM}$ to the death due to any cause or last follow-up. Survival curves were generated by the Kaplan-Meier product limit method. The difference in survival distribution was evaluated by the log rank test.

\section{Results}

\section{Demographic and clinical features}

A total of 357 patients were included in this study. Thirty-seven patients were excluded according exclusion criteria mentioned above (Fig. 1). Among the enrolled patients, 232 (72.5\%) were male and 88 (27.5\%) were female, with an average age of 45.92 years. There were no significant differences in gender between malignancy and non-malignancy CM patients. CM patients with malignancy were older than non-malignancy patients (56.25 vs. 45.52, $P \otimes 0.05)$ (Table 1). 
Table 1

The clinical characteristics and laboratory data of the CM patients without or with malignancy.

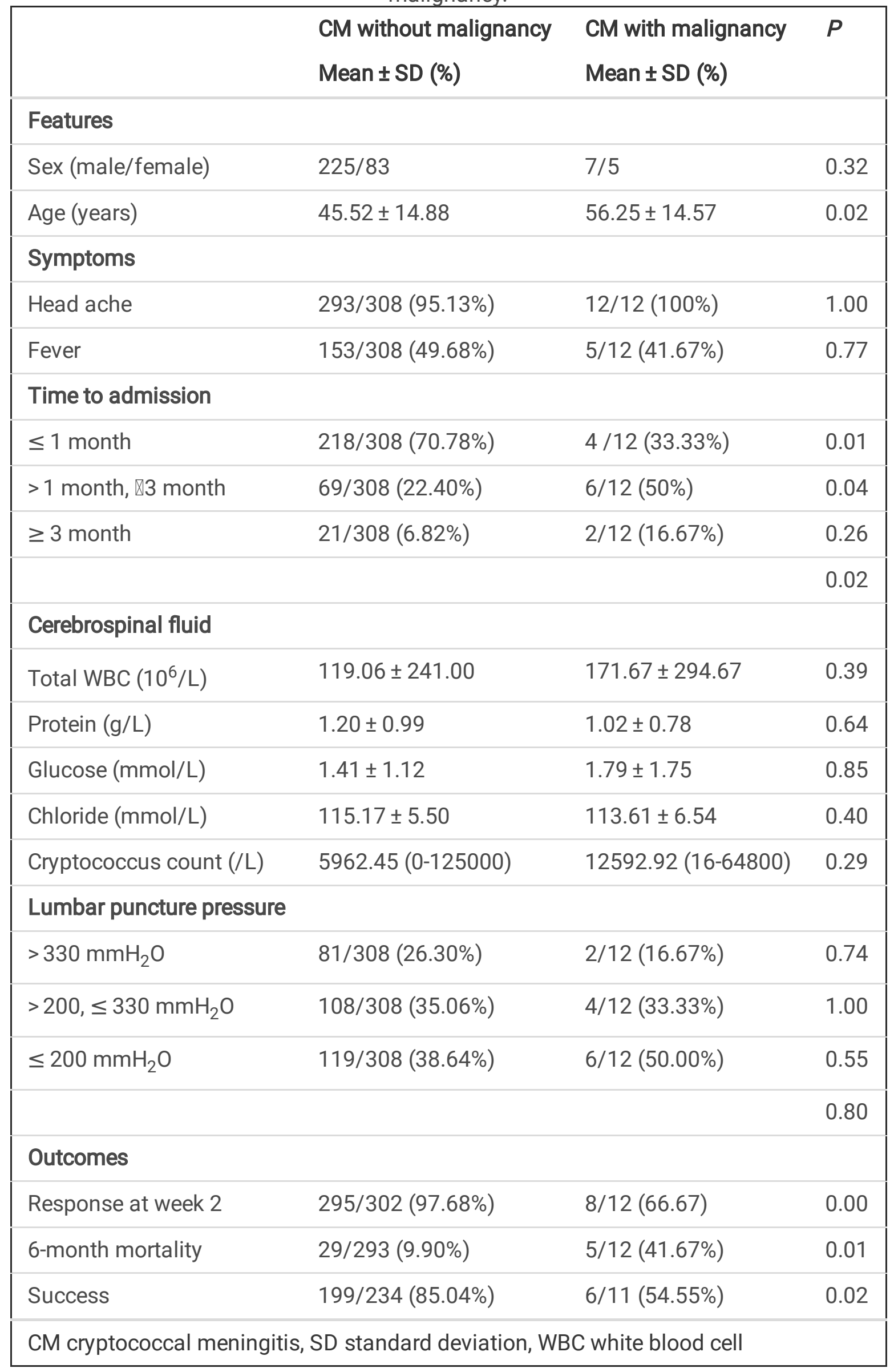




\section{Symptoms and time to admission}

Headache and fever were the two most common initial symptoms, with incidence rates of $95.31 \%$ and $49.38 \%$, respectively. The incidence rates of headache and fever were not significantly different between non-malignancy and malignancy patients (Table 1). Time to admission (time from initial symptoms to hospitalization and diagnosis of CM) were significantly different between non-malignancy and malignancy patients (Table 1).

\section{CSF findings}

At the first lumbar puncture, the CSF open pressure of patients with non-malignancy seemed higher than that of patients with malignancy but did not reach statistical difference (Table 1). Non-malignancy CM patients had lower cryptococcus counts than malignancy CM patients, but the difference was not statistically significant (Table 1). There were no significant differences in CSF white blood cell (WBC) count, protein, glucose, and chloride concentration between malignancy and non-malignancy CM patients (Table 1).

\section{Outcomes}

Most patients (302/308 and 12/12) completed the initial 2 weeks of antifungal treatment. Six patients died or were discharged from treatment within 2 weeks (4 death, 2 discharge). In the non-malignancy CM patients, after the initial 2 weeks of antifungal treatment, the clinical symptoms and signs of $97.68 \%$ patients improved, accompanied with decreasing CSF cryptococcus count, which represent the "response" to the treatment. However, the response rate of malignancy CM patients was significantly lower than that of non-malignancy patients $(66.67 \%$ vs. $97.68 \%)$.

Seven patients lost follow-up within 6 months, and 28 patients lost follow-up after 6 months. Mortality was finally evaluated in 305 patients at follow up for 6 months. Patients with malignancy had much higher 6-month mortality than non-malignancy patients (Table 1). At the end of this study, among the patients without malignancy, 35 patients died, 37 patients had not completed the therapy course yet, and 199 patients antifungal treatment acquired "success". Among the patients with malignancy, 5/12 (41.67\%) died within 6 months, 6 patients antifungal treatment was "success" (one died of tumor recurrence 14 months after successful CM treatment), and one patient still took oral antifungal drugs for about 1 year and was in stable condition. Survival curves for non-malignancy CM and malignancy CM were shown in Fig. 2. Patients with malignancy had significant lower survival rate than non-malignancy ones $(P<0.001)$.

\section{Characteristics of MBC and MAC patients}

The clinical characteristics of MBC were shown in Table 2. The number of MBC cases was 7, age ranged from 31 to 68 years, with a median of 48.43 years and three of them were male. Six cases were epithelial-derived malignancy. Another case was diffuse large B lymphoma. The diagnosis time from malignancy to CM ranged from 2 to 60 months, with an average of 26.86 months. Most malignancies were treated by surgery and in stable condition. The treatment on CM in these patients was successful. The case with diffuse large $B$ lymphoma has been undergoing antifungal treatment for approximately one year and has not yet cleared cryptococcus at the end of present study. 
Table 2

The clinical characteristics and prognosis of MBC patients.

\begin{tabular}{|c|c|c|c|c|c|c|c|c|}
\hline No. & Sex & Age & $\begin{array}{l}\text { Malignancy } \\
\text { origin }\end{array}$ & $\begin{array}{l}\text { Time from } \\
\text { malignancy } \\
\text { to CM } \\
\text { (month) }\end{array}$ & $\begin{array}{l}\text { Malignancy } \\
\text { treatment }\end{array}$ & $\begin{array}{l}\text { Count } \\
\text { (/L) }\end{array}$ & $\begin{array}{l}\text { CM } \\
\text { Outcomes }\end{array}$ & Note \\
\hline 1 & Male & 46 & Liver & 2 & $\begin{array}{l}\text { Surgery, } \\
\text { chemotherapy }\end{array}$ & 2560 & Success & $\begin{array}{l}\text { Malignancy } \\
\text { recurrence } \\
2 \text { years } \\
\text { later, death }\end{array}$ \\
\hline 2 & Female & 61 & Vaginal & 8 & $\begin{array}{l}\text { Surgery, } \\
\text { radiotherapy, } \\
\text { chemotherapy }\end{array}$ & 64800 & Success & $\begin{array}{l}\text { Up to } 68 \\
\text { weeks of } \\
\text { treatment } \\
\text { time }\end{array}$ \\
\hline 3 & Male & 40 & Pharynx & 36 & $\begin{array}{l}\text { Surgery, } \\
\text { radiotherapy }\end{array}$ & 58 & Success & $\begin{array}{l}\text { Completed } \\
\text { three stages } \\
\text { treatment } \\
\text { smoothly }\end{array}$ \\
\hline 4 & Female & 31 & Thyroid & 24 & Surgery & 26 & Success & $\begin{array}{l}\text { Completed } \\
\text { three stages } \\
\text { treatment } \\
\text { smoothly }\end{array}$ \\
\hline 5 & Female & 46 & Thyroid & 60 & Surgery & 187 & Success & $\begin{array}{l}\text { Completed } \\
\text { three stages } \\
\text { treatment } \\
\text { smoothly }\end{array}$ \\
\hline 6 & Male & 68 & Lung & 48 & $\begin{array}{l}\text { Surgery, } \\
\text { chemotherapy }\end{array}$ & 22838 & Death & $\begin{array}{l}\text { Malignancy- } \\
\text { related, } \\
\text { death }\end{array}$ \\
\hline 7 & Female & 47 & Lymphoma & 10 & Chemotherapy & 20608 & Response & $\begin{array}{l}\text { Still taking } \\
\text { oral } \\
\text { antifungal } \\
\text { drugs }\end{array}$ \\
\hline
\end{tabular}

The clinical characteristics of MAC were shown in Table 3. The number of MAC cases was 5 , age ranged from 52 to 77 , with a median of 67.20 years and four of them were male. MAC patients were significantly older than the MBC patients and more likely to be male. The five patients were confirmed to have epithelial-derived malignancies of the digestive or respiratory system. Four of the MAC patients had not clinical symptoms of the primary malignancy, and the clue of malignancy was mostly provided by PET-CT examination. One MAC patient with gallbladder tumor had mild clinical symptoms, and the tumor was removed by minimally invasive surgery. The treatment of CM in this case was successful. Other patients experienced a series of complications during antifungal therapy. The treatment of malignancies in these patients, such as surgery, radiotherapy or chemotherapy, has no chance to implement. They died within 6 months. 
Table 3

The clinical characteristics and prognosis of MAC patients.

\begin{tabular}{|lllllll|}
\hline No. & Sex & Age & $\begin{array}{l}\text { Malignancy } \\
\text { origin }\end{array}$ & $\begin{array}{l}\text { Count } \\
\text { (/L) }\end{array}$ & \multicolumn{2}{l}{ CM Outcomes } \\
\hline 1 & Male & 64 & Lung & 650 & Death & $\begin{array}{l}\text { Found clue by routine CT scan, malignancy- } \\
\text { related }\end{array}$ \\
\hline 2 & Male & 70 & Stomach & 12222 & Death & Found clue by PET-CT, malignancy-related \\
\hline 3 & Female & 73 & Gallbladder & 550 & Success & $\begin{array}{l}\text { Found clue by PET-CT, removal of malignancy } \\
\text { by surgery }\end{array}$ \\
\hline 4 & Male & 77 & Stomach & 16 & Death & $\begin{array}{l}\text { Found clue by PET-CT, other (severe pneumonia } \\
\text { during treatment) }\end{array}$ \\
\hline 5 & Male & 52 & Lung & 26600 & Death & Found clue by PET-CT, CM-related \\
\hline CM cryptococcal meningitis, MAC malignancy after cryptococcal meningitis, No. number
\end{tabular}

\section{Discussion}

Although CM is much more common in non-HIV patients with predisposing factors, including malignancy [2, 12], there has been little information about the clinical features and prognosis of these patients. To our knowledge, the present study was the largest and most detailed series of CM cases in non-HIV patients with malignancy. In this study, we found that a longer time to diagnosis and worse prognosis in CM patients with malignancies and PET-CT might be a useful tool for screening malignancy in such patients.

Early researches have shown that malignancies, especially lymphomas [7-9], appear to be closely associated with cryptococcosis. Since then, there have been many case reports of cryptococcal infections as malignancy complications [13-15]. These pioneering studies warned a close relationship between malignancy and CM, and this may be due to the malignancy-related immune alteration or lymphocyte-depleting chemotherapeutic regimens [9]. Unlike previous studies that found CM in malignancy patients, our present study focused on CM patients, retrospectively analyzed and looked for potential malignant tumors. We found that most patients in our study had solid malignancies (except one lymphoma), and they were all epithelial origin. In immunocompromised genetically modified mice and immunodeficiency populations, the incidence of malignancy has increased significantly [16-18]. These phenomena were thought to be related to the decline in the ability of immunosurveillance. According to this perspective, CM and malignancy may share the same immune abnormality mechanism.

In current study, the incidence of CM with malignancy was $3.75 \%$, which was much higher than that of the general population [19]. Two recent retrospective studies have reported even higher rates of malignancy in CM patients $[20,21]$. We found that malignancy was usually found in older CM patients, older than 50 years should be more vigilant about the possibility of malignancy. Up to $50 \%$ of CM patients with malignancy were hospitalized between 1 and 3 months after clinical symptoms appear, while $70.78 \%$ of non-malignancy CM patients were within one month of onset. This discrepancy suggested a significant difference in the severity of clinical symptoms between the two groups, which might be more prominent in patients without malignancy. Comparing the intracranial pressure between the two groups did not reach a statistical difference, we considered the possible reason was that CM patients with malignancy were older. It is generally believed that the elderly are 
less sensitive to pain. Therefore, the clinical symptoms in CM patients with malignancy were atypical, which caused a delay in CM diagnosis.

Literature review analysis found that only less than $15 \%$ of patients with cryptococcus infection associated with malignancy were solid [9]. However, recent studies have found that the incidence of CM patients with solid malignancies was roughly equivalent with haematologic [20,21]. The present study described 12 malignancies in $320 \mathrm{CM}$ patients, of which only one was haematologic. In the $7 \mathrm{MBC}$ patients, the types of malignancy and the affected organs were varied, and they had good antifungal response and low mortality. In contrast, 5 MAC patients mainly involved the digestive and respiratory systems, with a mortality rate of $80 \%$. We suggest that three main reasons might respond for the poor prognosis of MAC: 1) they were older, and senior has been confirmed to indicate a poor prognosis of CM [21, 22], 2) when the malignancy was found, most of the patients lost the chance to treat the malignancy due to $\mathrm{CM}, 3$ ) the patients and his family abandoned active therapy.

Early screening of malignancies is difficult [23]. The sensitivity of different tests in screening of different types of malignancies is inconsistent. Of the 5 MAC patients in this study, only one patient found a lung cancer in routine chest CT. PET-CT is a non-invasive imaging test that has a unique advantage in the detection of early malignancies $[24,25]$. In a variety of solid tumor and organ infiltrating leukemias, lesions of less than $5 \mathrm{~mm}$ can be found by PET-CT with ${ }^{18}$ F-FDG radioactive probes $[26,27]$. In the 104 patients who underwent PET-CT examinations, five patients were prompted to have suspected malignancies, and 4 were eventually confirmed. Therefore, we recommend routine PET-CT examinations for CM patients older than 50 years in order to detect possible early malignancy in time.

Our study had limitation. In view of the economic cost, not all patients undergo detailed malignancy screening. The possibility of missed malignancy diagnosis may exist. The clues of this possibility can be observed in the lower malignancy rate in without PET-CT patients than in PET-CT ones.

\section{Conclusions}

In conclusion, the results of present study suggested an increase in the incidence of solid malignancies in CM patients and those patients had a poor prognosis if the malignancies were newly diagnosed. These malignancies were relatively insidious, PET-CT might provide useful clue for finding the malignancies in CM patients older than 50 years.

\section{Abbreviations}

18F-FDG: 18-fluorodeoxyglucose; CM: Cryptococcal meningitis; CSF: Cerebrospinal fluid; HIV: Human immunodeficiency virus; MAC: malignancy after cryptococcal meningitis; MBC: malignancy before cryptococcal meningitis; PET-CT: positron emission computed tomography; WBC: white blood cell

\section{Declarations}

\section{Acknowledgements}

The authors wish to thank the CM patients and their families for agreeing to participate in this study. The authors also wish to thank the staff of the Department of Neurology of the Third Affiliated Hospital of Sun Yat-sen 
University.

\section{Authors' contributions}

XX and LC collaborated in the conception, organization, execution of the research project, statistical analysis design, and drafted the manuscript. YW and $\mathrm{JL}$ collaborated in interpretation data, statistical analysis. QD collaborated in review and critique of the manuscript. CL collaborated in collection of medical records. YJ and FP collaborated in the conception, organization, and the review and critique of the manuscript.

\section{Funding}

This work was funded by National Natural Science Foundation of China (No. 81671182).

\section{Availability of data and materials}

All data are available upon reasonable request.

\section{Ethics approval and consent to participate}

The study was conducted in accordance with the Declaration of Helsinki and Good Clinical Practice guidelines, and the protocol was approved by the Medical Ethics Committee of the Third Affiliated Hospital of Sun Yat-sen University.

\section{Consent for publication}

All authors consented for publication.

\section{Competing interests}

The authors declare that they have no competing interests.

\section{Author details}

${ }^{1}$ Department of Neurology, The Third affiliated Hospital of Sun Yat-sen University, Guangzhou, P. R. China.

${ }^{2}$ Department of Neurology, The First Affiliated Hospital of Guizhou University of traditional Chinese Medicine, P.

R. China. ${ }^{3}$ Department of Medical Records, The Third affiliated Hospital of Sun Yat-sen University, Guangzhou, P. R. China.

\section{References}

1. Rajasingham R, Smith RM, Park BJ, Jarvis JN, Govender NP, Chiller TM, et al. Global burden of disease of HIV-associated cryptococcal meningitis: an updated analysis. Lancet Infect Dis. 2017;17(8):873-81.

2. Williamson PR, Jarvis JN, Panackal AA, Fisher MC, Molloy SF, Loyse A, et al. Cryptococcal meningitis: epidemiology, immunology, diagnosis and therapy. Nat Rev Neurol. 2017;13(1):13-24.

3. George IA, Spec A, Powderly WG, Santos CAQ. Comparative Epidemiology and Outcomes of Human Immunodeficiency virus (HIV), Non-HIV Non-transplant, and Solid Organ Transplant Associated Cryptococcosis: A Population-Based Study. Clin Infect Dis. 2018;66(4):608-11. 
4. Zhu LP, Wu JQ, Xu B, Ou XT, Zhang QQ, Weng XH. Cryptococcal meningitis in non-HIV-infected patients in a Chinese tertiary care hospital, 1997-2007. Med Mycol. 2010;48(4):570-9.

5. Shankaran V, Ikeda H, Bruce AT, White JM, Swanson PE, Old LJ, et al. IFNgamma and lymphocytes prevent primary tumour development and shape tumour immunogenicity. Nature. 2001;410(6832):1107-11.

6. Engels EA, Biggar RJ, Hall HI, Cross H, Crutchfield A, Finch JL, et al. Cancer risk in people infected with human immunodeficiency virus in the United States. Int J Cancer. 2008;123(1):187-94.

7. Kaplan MH, Rosen PP, Armstrong D. Cryptococcosis in a cancer hospital: clinical and pathological correlates in forty-six patients. Cancer. 1977;39(5):2265-74.

8. Kontoyiannis DP, Peitsch WK, Reddy BT, Whimbey EE, Han XY, Bodey GP, et al. Cryptococcosis in patients with cancer. Clin Infect Dis. 2001;32(11):E145-50.

9. Schmalzle SA, Buchwald UK, Gilliam BL, Riedel DJ. Cryptococcus neoformans infection in malignancy. Mycoses. 2016;59(9):542-52.

10. Saag MS, Graybill RJ, Larsen RA, Pappas PG, Perfect JR, Powderly WG, et al. Practice guidelines for the management of cryptococcal disease. Infectious Diseases Society of America. Clin Infect Dis. 2000;30(4):710-8.

11. Perfect JR, Dismukes WE, Dromer F, Goldman DL, Graybill JR, Hamill RJ, et al. Clinical practice guidelines for the management of cryptococcal disease: 2010 update by the infectious diseases society of america. Clin Infect Dis. 2010;50(3):291-322.

12. Henao-Martinez AF, Chastain DB, Franco-Paredes C. Treatment of cryptococcosis in non-HIV immunocompromised patients. Curr Opin Infect Dis. 2018;31(4):278-85.

13. Takase K, Yoshida T, Nakamura T, Seki S, Sato H, Yamamoto T. [Cryptococcal Meningitis in a Patient with Breast Cancer Receiving Everolimus: A Case of Successful Treatment with Continuous Cerebrospinal Fluid Drainage]. Brain Nerve. 2018;70(11):1301-5.

14. To CA, Hsieh RW, McClellan JS, Howard W, Fischbein NJ, Brown JM, et al. Cryptococcal osteomyelitis and meningitis in a patient with non-hodgkin's lymphoma treated with PEP-C. BMJ Case Rep. 2012;2012.

15. Marchand T, Revest M, Tattevin P, Chevrier S, Poullot E, Lamy T, et al. Early cryptococcal meningitis following treatment with rituximab, fludarabine and cyclophosphamide in a patient with chronic lymphocytic leukemia. Leuk Lymphoma. 2013;54(3):643-5.

16. Girardi M, Oppenheim DE, Steele CR, Lewis JM, Glusac E, Filler R, et al. Regulation of cutaneous malignancy by gammadelta T cells. Science. 2001;294(5542):605-9.

17. Street SE, Hayakawa Y, Zhan Y, Lew AM, MacGregor D, Jamieson AM, et al. Innate immune surveillance of spontaneous B cell lymphomas by natural killer cells and gammadelta T cells. J Exp Med. 2004;199(6):879-84.

18. Smyth MJ, Dunn GP, Schreiber RD. Cancer immunosurveillance and immunoediting: the roles of immunity in suppressing tumor development and shaping tumor immunogenicity. Adv Immunol. 2006;90:1-50.

19. Bray F, Ferlay J, Soerjomataram I, Siegel RL, Torre LA, Jemal A. Global cancer statistics 2018: GLOBOCAN estimates of incidence and mortality worldwide for 36 cancers in 185 countries. CA Cancer J Clin. 2018;68(6):394-424.

20. Hakyemez IN, Erdem H, Beraud G, Lurdes M, Silva-Pinto A, Alexandru C, et al. Prediction of unfavorable outcomes in cryptococcal meningitis: results of the multicenter Infectious Diseases International Research

Page $11 / 14$ 
Initiative (ID-IRI) cryptococcal meningitis study. Eur J Clin Microbiol Infect Dis. 2018;37(7):1231-40.

21. Tsai WC, Lien CY, Lee JJ, Hsiao WC, Huang CR, Tsai NW, et al. The clinical characteristics and therapeutic outcomes of cryptococcal meningitis in elderly patients: a hospital-based study. Bmc Geriatr. 2019;19.

22. Qu J, Zhou T, Zhong C, Deng R, Lu X. Comparison of clinical features and prognostic factors in HIV-negative adults with cryptococcal meningitis and tuberculous meningitis: a retrospective study. BMC Infect Dis. 2017;17(1):51.

23. Rebbeck TR, Burns-White K, Chan AT, Emmons K, Freedman M, Hunter DJ, et al. Precision Prevention and Early Detection of Cancer: Fundamental Principles. Cancer Discov. 2018;8(7):803-11.

24. Sanli Y, Zukotynski K, Mittra E, Chen DL, Nadel H, Niederkohr RD, et al. Update 2018: 18F-FDG PET/CT and PET/MRI in Head and Neck Cancer. Clin Nucl Med. 2018;43(12):e439-e52.

25. Evens AM, Kostakoglu L. The role of FDG-PET in defining prognosis of Hodgkin lymphoma for early-stage disease. Blood. 2014;124(23):3356-64.

26. Kunawudhi A, Wong AK, Alkasab TK, Mahmood U. Accuracy of FDG-PET/CT for Detection of Incidental PreMalignant and Malignant Colonic Lesions - Correlation with Colonoscopic and Histopathologic Findings. Asian Pac J Cancer Prev. 2016;17(8):4143-7.

27. Sim YT, Poon FW. Imaging of solitary pulmonary nodule-a clinical review. Quant Imaging Med Surg. 2013;3(6):316-26.

\section{Figures}




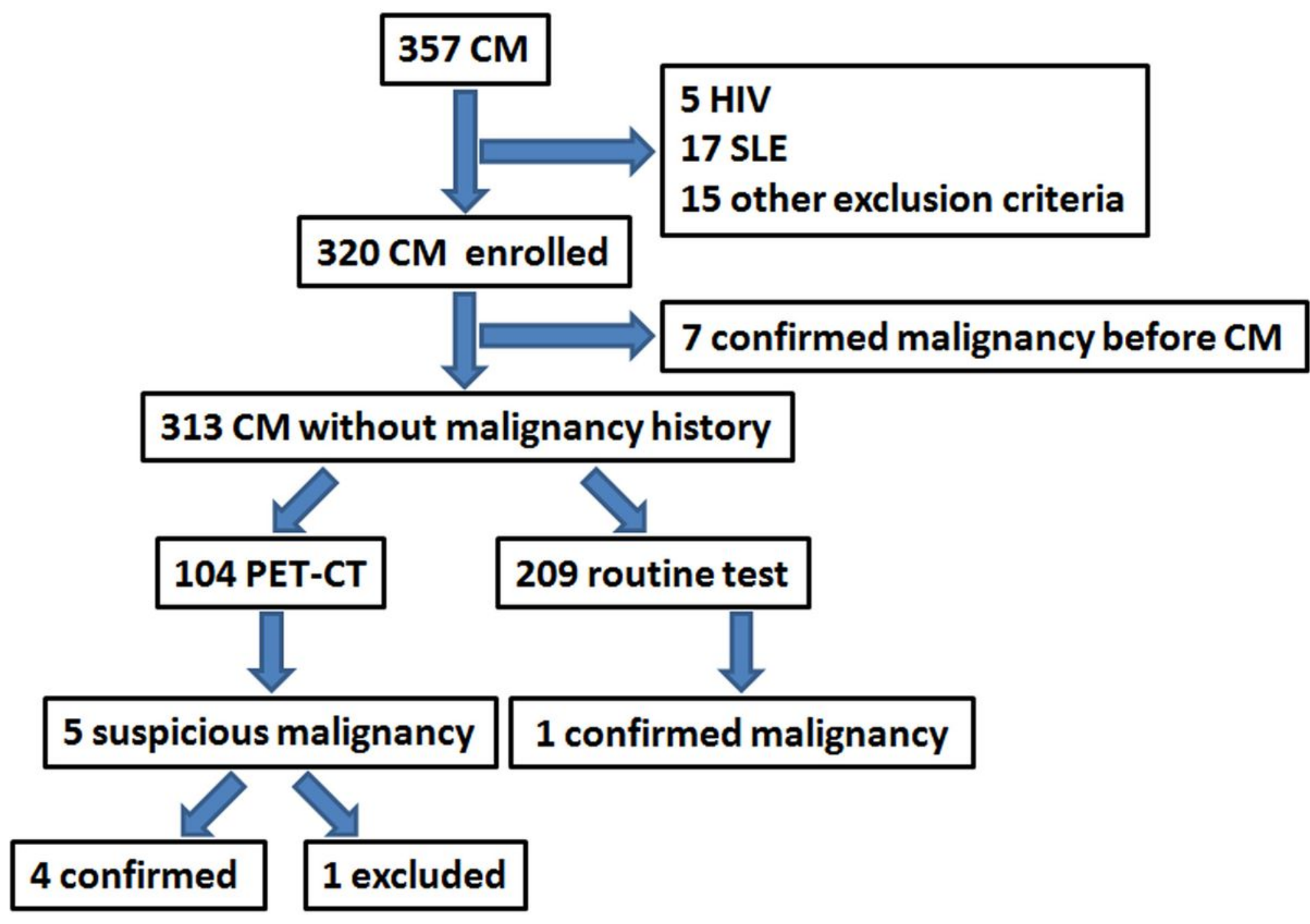

Figure 1

Flow chart displaying the enrollment of study participants. CM cryptococcal meningitis, HIV human immunodeficiency virus, PET-CT positron emission computed tomography, SLE systemic lupus erythematosus. 


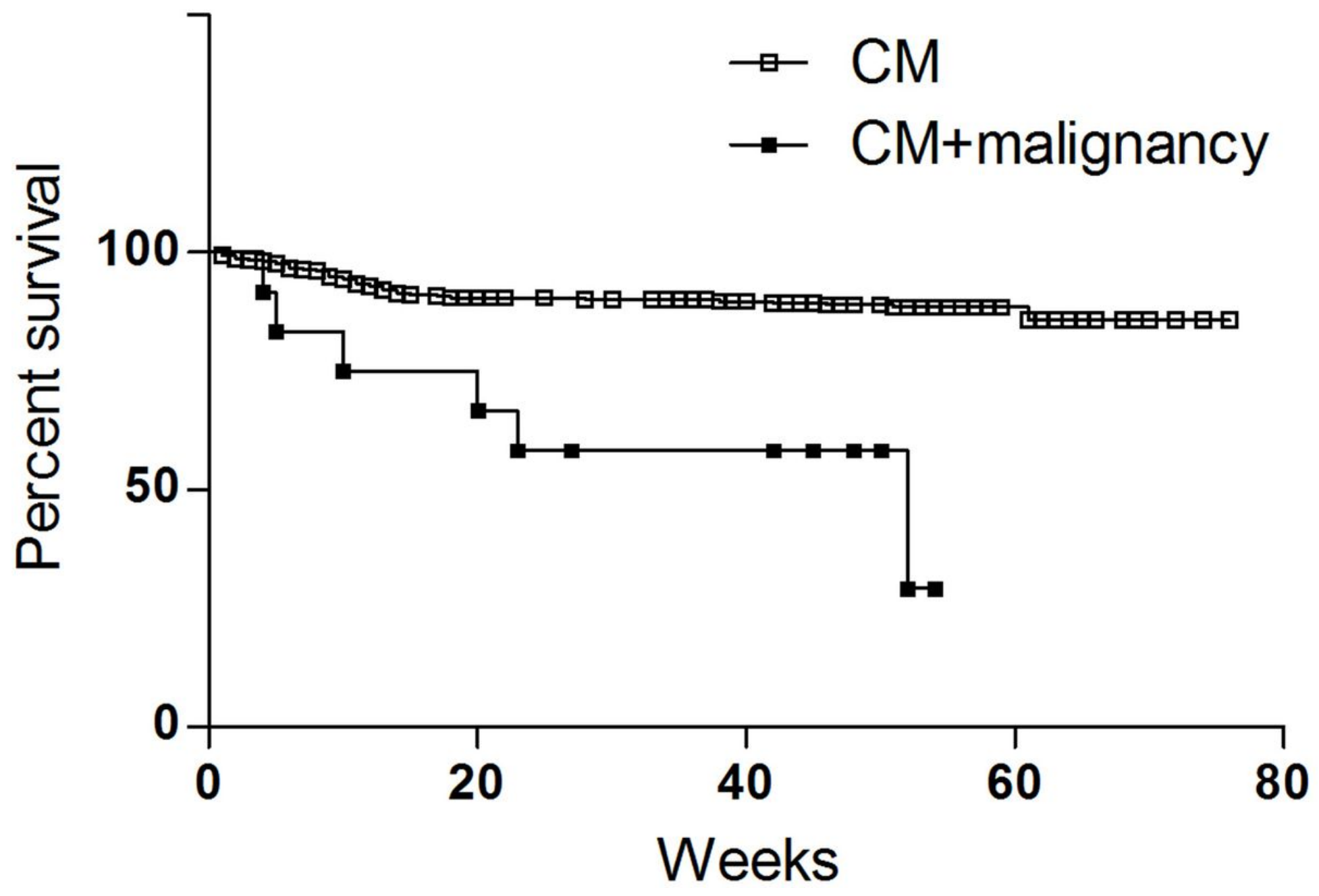

Figure 2

Survival curves for the $\mathrm{CM}$ without or with malignancy. $\mathrm{CM}$ cryptococcal meningitis. 